\title{
Análise de metais traço em lodos industrial e doméstico
}

Ainda é um desafio descartar corretamente lodo de esgoto contendo metais tóxicos. A aplicação do lodo tratado na agricultura tem sido o método mais comumente usado em todo o mundo e está sendo considerado como uma das formas mais econômicas de descarte de lodo. Nesse sentido, o objetivo do trabalho foi caracterizar três tipos diferentes de lodos, sendo dois indústrias e um de esgoto doméstico, através de caracterizações químicas e determinação dos metais traço: chumbo, cromo, cobre, níquel e zinco. Os metais traço foram determinados por espectrofotometria de absorção atômica em chama. As análises realizadas nos lodos apresentaram um valor considerável de matéria orgânica e umidade, além de micro e macronutrientes como carbono, nitrogênio, fósforo, potássio, cálcio e magnésio que são indispensáveis para a agricultura. Os teores para os metais traço variaram de: chumbo 8,8 a $4,3 \mathrm{mg} \mathrm{kg}-1, \mathrm{cromo} 65$ a $41,6 \mathrm{mg} \mathrm{kg}-1, \mathrm{cobre} 138,5$ a $22 \mathrm{mg} \mathrm{kg}-1$, níquel 25,1 a 4,8 mg kg-1 e zinco 236,1 a 146,3 mg kg-1 sendo esses teores inferiores aos valores máximos para disposição a agricultura segundo legislação brasileira. Os resultados sugerem que os lodos testados podem ser destinados como fontes de nutrientes em cultivos agrícolas, pois além de teores de matéria orgânica e características químicas adequadas possuem baixos teores de metais traço.

Palavras-chave: Biossólidos; Atributos Químicos; Bioacumulação; Metaloides.

\section{Analysis of trace metals in domestic and industrial sewage sludges}

The adequate disposal of sewage sludges containing toxic metals still is a challenge. Its application on agriculture has been the most common method around the world and is being considered one of the cheapest ways for disposing this sludge. In that sense, the goal of the current research was to characterize three types of sludge, two coming from industry and one, from domestic sources, through chemical characterizations and determination of the trace metals: lead, chrome, copper, nickel and zinc. These metals were determined by Flame Atomic Absorption Spectrometry. The analyses showed a considerable value of organic matter and humidity, presenting also micro and macronutrients as carbon, nitrogen, phophorus, potassium, calcium and magnesium, which are indispensable to agriculture. The levels of these metals varied from: lead 8,8 to $4,3 \mathrm{mg} \mathrm{kg}-1$, chrome 65 to $41,6 \mathrm{mg} \mathrm{kg}-1$, copper 138,5 to $22 \mathrm{mg} \mathrm{kg}-1$, nickel 25,1 to $4,8 \mathrm{mg} \mathrm{kg}-1$ and zinc 236,1 to $146,3 \mathrm{mg} \mathrm{kg-1}$ being all these values lower than the limits determined by Brazilian legislation for agricultural disposal. The results suggest the applicability of these sludges as a nutrient source on agricultural crops, since, beyond from presenting adequate organic matter and chemical properties, these sludges also present low levels of trace metals.

Keywords: Biosolids; Chemical Properties; Bioaccumulation; Metalloids.

Topic: Química Agrícola e Ambiental

Reviewed anonymously in the process of blind peer.
Received: $23 / 12 / 2018$

Approved: 10/01/2019
Giani Mariza Barwald Bohm (iD

Instituto Federal Sul-rio-grandense, Brasil http://lattes.cnpq.br/0429818788026737

http://orcid.org/0000-0002-2844-416X

bohmgiani@gmail.com

Valquiria Ferreira Rojas (iD

Instituto Federal Sul-rio-grandense, Brasil

http://lattes.cnpq.br/1050647441130006

http://orcid.org/0000-0003-4007-1295

valquiriarojas@bol.com.br

\section{Emerson de Moraes Bohm (iD)}

Instituto Federal Sul-rio-grandense, Brasil

http://lattes.cnpq.br/5903017262393675

http://orcid.org/0000-0001-8308-9669

ebohm2@gmail.com

\author{
José Pedro Sanches Filho \\ Instituto Federal Sul-rio-grandense, Brasil \\ http://lattes.cnpq.br/9785390634457316 \\ pjsans@ibest.com.br \\ lago Riveiro Santos Dutra (iD \\ Instituto Federal do Sul, Brasil \\ http://lattes.cnpq.br/9043224024765006 \\ http://orcid.org/0000-0003-3290-463X \\ iagorivsd@gmail.com
}

Referencing this:

BHOM, G. M. B.; ROJAS, V. F.; BOHM, E. M.; SANCHES FILHO, J. P.; DUTRA, I. R. S.. Análise de metais traço em lodos industrial e doméstico. Revista Ibero Americana de Ciências Ambientais, v.10, n.1, p.21-28, 2019. DOI: http://doi.org/10.6008/CBPC21796858.2019.001.0003 


\section{INTRODUÇÃO}

A disposição final dos lodos das indústrias de beneficiamento assim como do lodo de esgoto doméstico tratado (LED), tem sido uma preocupação, devido a sua grande quantidade e a dificuldade em descartar esse material, que se não acondicionado corretamente pode ser poluente tanto para os recursos hídricos quanto para o solo (SILVEIRA et al., 2013; FERRAZ et al., 2014).

A reciclagem agrícola de lodos tratados tem se tornado uma alternativa interessante de disposição final, sobretudo antes de ser disposto como adubo no solo este deve passar por avaliações para determinar matéria orgânica, metais traço assim como a quantidade de micro e macronutrientes capazes de incrementar os elementos necessários ao solo agrícola (BOHM et al., 2018; CAMARGO et al., 2010).

Muitos metais com densidade superior a $6 \mathrm{mg} \mathrm{cm}^{-3}$ e número atômico maior que 20 são encontrados em baixas concentrações sendo denominados de metais traço. Esses elementos mesmo em baixas concentrações podem ser tóxicos e constituir uma fonte de poluição ambiental. Uma das preocupações à respeito dos metais é a sua capacidade de bioacumulação, pois os organismos possuem a capacidade de reter o contaminante por absorção ou ingestão sem conseguir eliminá-lo, fenômeno que é intensificado pela biomagnificação, processo em que a concentração de contaminantes nos tecidos aumenta à medida que se avança nos níveis tróficos da cadeia alimentar existente nestes compartimentos ambientais, o que faz com que as concentrações de metais nos seres vivos ou nas plantas possam se tornar altamente tóxicos (PINTO et al., 2013).

Quando os lodos provêm de processos de beneficiamento industriais, eles podem conter elementos com maior potencial de toxicidade devido suas matérias primas concentrar esses elementos. Uma vez que esses lodos são dispostos no ambiente podem resultar em contaminação do solo e dos recursos hídricos com metais traço, o que requer avaliações periódicas a fim de evitar a contaminação do ambiente (VILLANUEVA et al., 2012). Alguns autores realizaram estudos anteriores para caracterização de lodos (BOHM et al., 2016; MERLINO et al., 2010) encontrando diferentes concentrações de metais traço, algumas vezes superiores aos níveis máximos admissíveis de metais traços em lodos destinados a utilização agrícola (CONAMA n.460/2013).

Os processos de adsorção-dessorção dos solos são responsáveis pela disponibilidade dos metais para as plantas, os nutrientes presentes nesses lodos também têm grande influência sobre a parcela de metais traço a ser absorvida, pois em um solo pobre em nutrientes o processo de dessorção controla a liberação de metais para as plantas, assim como um pH baixo favorece a dessorção dos metais (FREITAS et al., 2009).

Vários autores vêm focando seus estudos na aplicação de lodos tratados na agricultura como fonte de nutrientes para as plantas, como por exemplo, no cultivo de milho (MERLINO et al., 2010), cultivo do girassol (BOHM et al., 2016). Para tanto, esses lodos devem apresentar elevada quantidade de matéria orgânica, essenciais ao solo para fertilização, além disso, os teores de metais traços devem obedecer aos limites definidos pelo Conselho Nacional do Meio Ambiente (CONAMA n.460/2013). 
Nesse contexto, o objetivo deste trabalho foi caracterizar três tipos diferentes de lodos, sendo dois indústrias e um de esgoto doméstico, através de caracterizações químicas e determinação dos metais traços: chumbo, cromo, cobre, níquel e zinco. Este estudo parte da hipótese que lodos gerados através de diferentes processos de tratamento e com origens diversas (industrial ou urbano) podem conter características distintas e resultar em diferentes quantidades de metais traço.

\section{METODOLOGIA}

Como material para esse estudo utilizou-se três tipos de lodos tratados com diferentes origens: 0 lodo de esgoto doméstico (LED), o lodo da Indústria de Pescado (LIP) e o lodo de esgoto industrial tratado de beneficiamento do arroz (LEITBA). O LED foi proveniente do efluente de esgoto doméstico tratado pela Companhia Riograndense de Saneamento (CORSAN) da cidade de Rio Grande/RS. O LIP foi obtido do tratamento do efluente do beneficiamento da sardinha de uma indústria pesqueira da cidade do Rio Grande/RS. O LEITBA foi resultante do tratamento de efluentes de uma indústria arrozeira da cidade de Pelotas/RS.

As amostras dos lodos, foram coletadas no mês de agosto de 2017, com o auxílio de pá plástica e acondicionada em bolsas de polietileno, mantidas sob refrigeração e transportados para a área experimental do Curso de Química, do Instituto Federal Sul-Rio-Grandense, campus Pelotas. Todos os materiais usados para coleta e armazenamento e a vidraria usada para as análises permaneceram previamente em imersão por 24 horas em ácido nítrico $\left(\mathrm{HNO}_{3}\right)$ a 10\%, com a finalidade de evitar a contaminação por metais.

Para determinação das características físico-químicas do solo utilizou-se as metodologias propostas por (Tedesco, 1995). Para o pH utilizou-se a potenciometria utilizando-se a relação amostra: água de 1:5, para o carbono orgânico utilizou-se a combustão úmida (Walkey Black), o nitrogênio total e fósforo total foram determinados por digestão sulfúrica (Kjeldahl) por espectometria de absorção de massa (EAM), o potássio total e cálcio total utilizou-se a digestão sulfúrica e determinação por espectrometria de absorção atômica (EAA), os resultados foram expressos em $\mathrm{g} \mathrm{Kg}^{-1}$.

No processo de extração dos metais, utilizou-se o método da digestão ácida, também conhecida como digestão pseudototal, foram feitas extrações com $2 \mathrm{~g}$ de amostras previamente secas a 65 $\mathrm{C}$, em

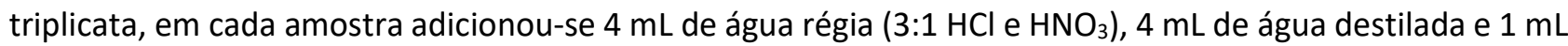
de ácido perclórico $\left(\mathrm{HClO}_{4}\right)$. A solução formada foi aquecida em banho-maria por $30 \mathrm{~min}$ a $90^{\circ} \mathrm{C}$ (HORTELLANI et al., 2008). Após a digestão, o extrato foi separado do resíduo do lodo por filtração e submetido a uma nova etapa de extração. A solução resultante da filtração foi transferida e avolumada com água ultra pura à $25 \mathrm{~mL}$. Os limites de detecção (Ld) e quantificação (Lq) foram definidos a partir de dez medidas dos brancos no EAA, calculando-se então o desvio padrão. O cálculo do limite de detecção foi considerado como sinal analítico mínimo três vezes o desvio padrão dos brancos mais a média do branco, para o Lq procedeu-se da mesma forma, porém utilizando 10 vezes o desvio padrão considerando uma amostra de $2 \mathrm{~g}$ (Pearson, 1997). A determinação dos metais traço $\mathrm{Pb}, \mathrm{Cr}, \mathrm{Cu}, \mathrm{Ni}$ e $\mathrm{Zn}$ foram realizadas por EAA por chama com equipamento da marca Perkin Elmer, modelo A Analyst 200 utilizando os parâmetros descritos na tabela 1. Os padrões foram 
preparados por meio de diluições das soluções padrões Titrisol $1000 \mathrm{mg} \mathrm{L}^{-1}(\mathrm{~Pb}, \mathrm{Cr}, \mathrm{Cu}, \mathrm{Ni}$ e $\mathrm{Zn}$ ), sofrendo o mesmo tratamento das amostras. Para leitura no EAA, construiu-se curva de calibração com cinco pontos com concentrações entre 0,2 e $5,0 \mathrm{mg} \mathrm{L}^{-1}$.

Tabela 1: Parâmetros utilizados nos ajustes do EAA (GBC 932 Plus), para as determinações de Pb, Cr, Cu, Ni e Zn.

\begin{tabular}{|l|l|l|l|l|l|}
\hline Elementos & Chumbo & Cromo & Cobre & Níquel & Zinco \\
\hline Corrente lâmpada & $15 \mathrm{~mA}$ & $15 \mathrm{~mA}$ & $15 \mathrm{~mA}$ & $15 \mathrm{~mA}$ & $15 \mathrm{~mA}$ \\
\hline Chama & ar acet. & óxido nitroso acet. & ar acet. & ar acet. & ar acet. \\
\hline Comprimento de onda & $283,31 \mathrm{~nm}$ & $357,8 \mathrm{~nm}$ & $324,7 \mathrm{~nm}$ & $232 \mathrm{~nm}$ & $213,8 \mathrm{~nm}$. \\
\hline
\end{tabular}

Legenda: acet.: acetileno.

\section{RESULTADOS E DISCUSSÃO}

A tabela 2 apresenta os resultados da caracterização físico-química preliminar dos lodos usados nesse estudo. Os resultados mostraram que o pH do LED foi de 6,6 e o do LIP 7,1 (Tabela 1), ambos estão dentro da faixa desejada que é de 5,5 a 7,0, conforme Tedesco (1995). Para o LEITBA o valor de pH 8,8 foi mais elevado semelhante ao resultado obtido por Vieira et al. (2011) que encontrou pH na faixa de 8,5 para lodo anaeróbio da parboilização do arroz. Assim o LEITBA pode ser um lodo alcalino provavelmente pela presença dos metais alcalinos e alcalinos terrosos provenientes do processo de tratamento do arroz. Esse resultado está de acordo com os baixos teores de $\mathrm{MO}(27,3 \%)$ e o somatório de $\mathrm{K}$, Ca e $\mathrm{Mg}\left(18,3 \mathrm{~g} \mathrm{~kg}^{-1}\right)$ obtidos neste estudo.

Os resultados para umidade foram $66 \%, 74 \%$ e $84 \%$ para LED, LEITBA e LIP, respectivamente. Estes teores foram inferiores aos obtidos por Ingelmo et al. (2012) e Vieira et al. (2011) os quais obtiveram, respectivamente, $94,5 \%$ e $95,2 \%$ para LED e LEITBA. Os maiores teores de MO 86\% foram obtidas pelo LIP e os menores teores $27,3 \%$ pelo LEITBA. Para Duarte-Davidson et al. (1996), um alto teor de MO confere ao lodo característica desejável para sua aplicação como fonte de nutrientes no solo agrário. Maiores teores de MO é desejável para destinação desse material em cultivos agrícolas uma vez que a atividade biológica do solo está relacionada com os teores de MO (BOHM et al., 2016). Por outro lado, menores teores de MO obtidos no LEITBA pode estar relacionado a uma maior estabilização do lodo, pois o conteúdo de MO decresce significativamente durante o processo de estabilização do lodo através da respiração microbiológica convertendo-a em $\mathrm{CO}_{2}$ através do processo de mineralização (INGELMO et al., 2012).

A proporção entre Carbono e Nitrogênio $(C / N)$, foi de 8:1 para o LED, 7:1 para LEITBA e LIP, esses valores estão abaixo dos indicados pela literatura que indicam relações C/N entre 20:1 e 40:1 para formação de composto orgânico (SCHMITZ et al., 2002). Porém Bohm et al. (2018) encontraram relações na faixa de 7:1 a 9:1 para substratos formulados com adição de lodos. Essa menor relação $\mathrm{C} / \mathrm{N}$ encontrada nesses lodos não indicam que não possam ser dispostos na agricultura, porém para isso deve ser calculado a proporção adequada a ser aplicada ao solo.

Para os teores de Carbono (C) obteve-se, respectivamente $307 \mathrm{~g} \mathrm{~kg}^{-1}, 96 \mathrm{~g} \mathrm{~kg}^{-1}$ e $54 \mathrm{~g} \mathrm{~kg}^{-1}$ para LED, LEITBA e LIP. Levando-se em consideração os valores de C indicados para destinação de lodo em solos agrícolas os resultados obtidos para LEITBA e LIP estão abaixo dos limites preconizados por esse órgão, que 
são de $150 \mathrm{~g} \mathrm{~kg}^{-1}$. O C, além de ser fonte de energia para a atividade microbiana através da respiração, também representa 50\% das massas das células dos microrganismos (MOREIRA et al., 2004).

Os valores de $\mathrm{N}$ foram $38,70 \mathrm{~g} \mathrm{~kg}^{-1}, 13,72 \mathrm{~g} \mathrm{~kg}^{-1}$ e 55,94 $\mathrm{g} \mathrm{kg}^{-1}$ para LED, LEITBA e LIP respectivamente. Todos os lodos obtiveram resultados superiores ao mínimo estabelecido para fertilizantes orgânicos pelo regulamento. Esse resultado é importante do ponto de vista de inserção de $\mathrm{N}$ no solo através da adição de lodo tratado.

Quanto ao Fósforo (P), os maiores teores $67,62 \mathrm{~g} \mathrm{~kg}^{-1}$ foram obtidos pelo LEITBA e os menores 6,75 $\mathrm{g} \mathrm{kg}^{-1}$ pelo LIP. Para Schmitz et al. (2002) a faixa ideal de P em substratos para cultivo de mudas é de 6 a 10 $\mathrm{g} \mathrm{kg}^{-1}$. Esse elevado teor de P no LEITBA está relacionado ao uso de produtos à base de fosfina (Hidreto de Fósforo) usados no tratamento de pragas nos grãos de arroz. Quanto ao K obteve-se teores de $3,86 \mathrm{~g} \mathrm{~kg}^{-1}$, $2,55 \mathrm{~g} \mathrm{~kg}^{-1} \mathrm{e} 0,96 \mathrm{~g} \mathrm{~kg}^{-1}$, respectivamente, para LED, LEITBA e LIP. O valor de $\mathrm{K}$ para substratos para cultivo de plantas deve estar na faixa de 1,6 e $3,0 \mathrm{~g} \mathrm{~kg}^{-1}$. Essas faixas estabelecidas por Schmitz et al. (2002) servem apenas de referência na formulação de substratos. No caso da destinação dos lodos tratados, avaliados neste estudo, tenha essa finalidade devem ser feitos cálculos posteriores para definir as dosagens a serem utilizadas nos cultivos agrícolas.

Para o elemento Cálcio (Ca), obteve-se teores de $0,32 \mathrm{~g} \mathrm{~kg}^{-1}, 2,14 \mathrm{~g} \mathrm{~kg}^{-1}$ e 9,29 $\mathrm{g} \mathrm{kg}^{-1}$, para LED, LEITBA e LIP, respectivamente. Na agricultura o Ca promove a redução da acidez do solo, promove o crescimento das raízes e ajuda na atividade microbiana (KRAMER et al., 2014). Portanto, a presença desse elemento nos lodos é importante como elemento condicionante da qualidade do solo. Para o Magnésio (Mg), obteve teores de 3,50 $\mathrm{g} \mathrm{kg}^{-1}, 16,23 \mathrm{~g} \mathrm{~kg}^{-1}$ e 1,49 $\mathrm{g} \mathrm{kg}^{-1}$ para LED, LEITBA e LIP, respectivamente. O magnésio é um mineral de extrema importância para o desenvolvimento das plantas, sua falta no solo pode causar clorose e prejudicar o desenvolvimento das mesmas (GRANSEE et al., 2013).

Assim, lodos de diferentes processos LED, LEITBA ou LIP contém diferentes quantidades de nutrientes que podem valorizar seus potenciais como fertilizante agrícola. O conhecimento da disponibilidade dos macro e micronutrientes no solo e nos lodos a serem dispensados na agricultura são fundamentais para uma recomendação de adubação adequada, evitando assim problemas de deficiência ou de toxidez (BORTOLON et al., 2009).

Tabela 2: $\mathrm{pH}$, teor de umidade, MO e atributos químicos em LED, LEITBA e LIP.

\begin{tabular}{|l|l|l|l|l|l|l|l|l|l|l|l|}
\hline Lodos & $\mathrm{pH}$ & Umidade & $\mathrm{MO}$ & $\mathrm{C} / \mathrm{N}$ & $\mathrm{C}$ & $\mathrm{N}$ & $\mathrm{P}$ & $\mathrm{K}$ & $\mathrm{Ca}$ & $\mathrm{Mg}$ \\
\hline & & $(\%)$ & $(\%)$ & \multicolumn{2}{|l|}{ Valores totais $\left(\mathrm{g} \mathrm{kg}^{-1}\right)$} & \multicolumn{5}{l|}{} \\
\hline LED & 6,6 & 66 & 60,0 & $8: 1$ & 307 & 38,70 & 28,26 & 3,64 & 0,32 & 3,50 \\
\hline LEITBA & 8,8 & 74 & 27,3 & $7: 1$ & 96 & 13,72 & 67,62 & 2,55 & 2,14 & 16,23 \\
\hline LIP & 7,1 & 84 & 86,0 & $1: 1$ & 54 & 55,94 & 6,75 & 0,96 & 9,29 & 1,49 \\
\hline
\end{tabular}

A tabela 3 apresenta os resultados determinados dos metais traços $\mathrm{Pb}, \mathrm{Cr}, \mathrm{Cu}, \mathrm{Ni}$ e $\mathrm{Zn}$ nas diferentes amostras de lodos, bem como as figuras de mérito para o método analítico. Podemos verificar que o método de digestão ácida apresentou uma resposta linear com $\mathrm{r}^{2}$ entre 0,999 para Pb e 0,867 para Ni. Os limites de deteç̧ão (Ld) variaram entre 0,3430 $\mathrm{mg} \mathrm{kg}^{-1}$ para $\mathrm{Cr}$ e 0,009 $\mathrm{mg} \mathrm{kg}^{-1}$ para Cu. Os limites de quantificação (Lq) variaram entre $0,6265 \mathrm{mg} \mathrm{kg}^{-1}$ para $\mathrm{Cr}$ e 0,021 $\mathrm{mg} \mathrm{kg}^{-1}$ para $\mathrm{Cu}$, sendo essas faixas de valores aceitáveis para 
a determinação de metais traço. Os coeficientes angulares (a) sugerem que o método foi mais sensível para o $\mathrm{Zn}(0,139)$ e menos para o $\operatorname{Cr}(0,002)$.

Os metais traço $\mathrm{Pb}, \mathrm{Cr}, \mathrm{Cu}, \mathrm{Ni}$ e $\mathrm{Zn}$ foram encontrados em todas as amostras de lodo. Dentre elas o LED apresentou maior concentração total de metais traço 429,8 $\mathrm{mg} \mathrm{kg}^{-1}$ e o LIP a menor concentração total $230,5 \mathrm{mg} \mathrm{kg}^{-1}$. Essa maior carga de metais no LED pode ser devido aos resíduos oriundos do esgoto doméstico. Esses resultados corroboram com a afirmação feita por Pinto et al. (2013) que cita os esgotos urbanos como a principal fonte de metais no ambiente.

Os maiores teores dos metais traço $\mathrm{Pb}, \mathrm{Cu}$ e $\mathrm{Zn}$ foram obtidos pelo LED sendo respectivamente, 8,8 $\pm 4,9 \% \mathrm{mg} \mathrm{kg}^{-1} ; 138,5 \pm 5,7 \% \mathrm{mg} \mathrm{kg}^{-1}$ e $236,1 \pm 2,5 \% \mathrm{mg} \mathrm{kg}^{-1}$ e os menores teores para esses metais para o LIP. Outros autores como Li et al. (2015) em estudo com LED destacam a presença de Zn e Cu como elementos de maior concentração e relacionam a presença do Zn à dissolução corrosiva dos tubos de drenagem galvanizados. Betemps et al. (2012) em seus estudos com sedimentos em lagoas que receberam esgoto doméstico encontraram $\mathrm{Zn}$ e $\mathrm{Pb}$ como elementos majoritários. Esse maior teor de $\mathrm{Zn}$ no LED pode ser importante para sua disposição em solos agrícolas pois o Zn é um nutriente essencial, participa de diversos ciclos bioquímicos das plantas, incluindo fotossíntese e formação de açúcar, participa também na síntese do hormônio de crescimento (AIA) devido a sua função na ativação das enzimas sintetase do triptofano e metabolismo de triptamina (MARANGONI et al., 2013).

Tabela 3: Teores de Chumbo (Pb), Cromo ( $\mathrm{Cr}$ ), Cobre ( $\mathrm{Cu})$, Níquel (Ni) e Zinco ( $\mathrm{Zn}$ ) obtidos por EAA para LED, LEITBA e LIP.

\begin{tabular}{|l|l|l|l|l|l|l|}
\hline Parâmetros analíticos & $\begin{array}{l}\mathrm{Pb} \\
\mathrm{mg} \mathrm{kg}^{-1} \\
\pm R S D(\%)\end{array}$ & $\begin{array}{l}\mathrm{Cr} \\
\mathrm{mg} \mathrm{kg}^{-1} \\
\pm R S D(\%)\end{array}$ & $\begin{array}{l}\mathrm{Cu} \\
\mathrm{mg} \mathrm{kg}^{-1} \\
\pm R S D(\%)\end{array}$ & $\begin{array}{l}\mathrm{Ni} \\
\mathrm{mg} \mathrm{kg}^{-1} \\
\pm R S D(\%)\end{array}$ & $\begin{array}{l}\text { Zn } \\
\mathrm{mg} \mathrm{kg}^{-1} \\
\pm R S D(\%)\end{array}$ & $\begin{array}{l}\text { Concentrações } \\
\text { totais }\end{array}$ \\
\hline LED & $8,8^{\mathrm{a}} \pm 4,9$ & $41,6^{\mathrm{b}} \pm 10$ & $138,5^{\mathrm{a}} \pm 5,7$ & $4,8^{\mathrm{c}} \pm 5,2$ & $236,1^{\mathrm{a}} \pm 2,5$ & 429,80 \\
\hline LEITBA & $6,7^{\mathrm{b}} \pm 2,2$ & $60,8^{\mathrm{a}} \pm 8,6$ & $22,0^{\mathrm{b}} \pm 2,6$ & $25,1^{\mathrm{a}} \pm 8,6$ & $203,4^{\mathrm{b}} \pm 1,3$ & 318,00 \\
\hline LIP & $4,5^{\mathrm{c}} \pm 5,0$ & $42,0^{\mathrm{b}} \pm 1,8$ & $26,7^{\mathrm{b}} \pm 2,5$ & $11,0^{\mathrm{b}} \pm 5,8$ & $146,3^{\mathrm{c}} \pm 3,7$ & 230,50 \\
\hline $\mathrm{a}$ & 0,007 & 0,002 & 0,061 & 0,021 & 0,139 & \\
\hline $\mathrm{b}$ & 0,00007 & 0,0021 & 0,0017 & 0,028 & 0,017 & \\
\hline $\mathrm{R}^{2}$ & 0,999 & 0,997 & 0,989 & 0,867 & 0,984 & \\
\hline Lq & 0,4303 & 0,6265 & 0,0210 & 0,4594 & 0,1201 & \\
\hline Ld & 0,0981 & 0,3430 & 0,0090 & 0,0707 & 0,0177 & \\
\hline${ }^{*}$ NA & 72 & 75 & 60 & 30 & 300 & \\
\hline${ }^{*}$ NM & 180 & 150 & 200 & 70 & 450 & \\
\hline
\end{tabular}

Fonte: CONAMA n.460/2013. Legenda: Ld - limite de detecção; Lq - limite de quantificação; NA - Níveis de alerta; NM Níveis Máximos admissíveis de metais em lodos destinados a utilização agrícola.

Quanto aos teores de $\mathrm{Cu}$, obtidos nesse estudo para o LED, segundo a resolução do CONAMA n.460/13, esses se encontram em níveis de alerta. Nesse sentido, é importante monitorar os teores de Cu para disposição no uso agrícola, pois segundo Llorens et al. (2000), altos níveis de Cu inibem o crescimento das raízes, reduzem drasticamente a atividade das enzimas de fixação biológica do nitrogênio nas plantas.

Quanto aos metais traço $\mathrm{Cr}$ e $\mathrm{Ni}$ os maiores teores foram obtidos pelo LEITBA sendo, respectivamente, $60,8 \pm 8,6 \mathrm{mg} \mathrm{kg}^{-1}$ e $25,1 \pm 8,6 \% \mathrm{mg} \mathrm{kg}^{-1}$ e os menores teores para esses metais para o LED $41,6 \pm 10 \% \mathrm{mg} \mathrm{kg}^{-1} \mathrm{e} 4,8 \pm 5,2 \% \mathrm{mg} \mathrm{kg}^{-1}$. Esses maiores teores de $\mathrm{Cr}$ e Ni para o LEITBA pode estar relacionado ao uso de pesticidas nos grãos durante o cultivo agrícola (MARCHESAN et al., 2010) e ao material usado no processo beneficiamento e armazenagem dos grãos, no qual as tubulações e silos são na maioria metálicos. 
Os metais traço $\mathrm{Pb}, \mathrm{Cr}, \mathrm{Cu}, \mathrm{Ni}$ e $\mathrm{Zn}$ quantificados nesse estudo encontram-se dentro do limite permitido pela legislação brasileira (CONAMA n.460/2013), portanto podem ser destinados à agricultura com segurança e pela sua composição química de MO, C, N, P, K, Ca e Mg podem contribuir como fonte de nutrientes para as plantas. Entretanto, em questão de segurança, é necessário um controle nos teores dos metais traço desses lodos, a fim de evitar que com aplicações sucessivas ao solo ocasione bioacumulação ou biomagnificação dos metais tóxicos o que prejudicaria tanto a planta quanto a segurança alimentar.

\section{CONCLUSÕES}

Os metais traço $\mathrm{Pb}, \mathrm{Cr}$, Cu, Ni e Zn determinados nos lodos LED, LEITBA e LIP, estão abaixo dos níveis máximos estipulados pela legislação brasileira para destinação na agricultura, tornando-se uma alternativa ambientalmente adequada para destinação na agricultura. Pela composição química os lodos apresentam potencial como fontes de nutrientes para as plantas.

\section{REFERÊNCIAS}

BETEMPS, G. R.; SANCHES-FILHO, P. J.. Estudo sazonal de metais pesados no sedimento do Saco do Laranjal - PelotasRS. Journal of the Brazilian Society of Ecotoxicology, v.7, n.2, p.79-84, 2012. DOI: http://dx.doi.org/10.5132/ibse.2012.02.012

BOHM, G.; KARSBURG, R.; HEIDRICH, C.; BOHM, E.; MACHADO, R.. Effects of Different Sewage Sludge Concentrations on Soil and Cultivated Raphanus sativus L. American Journal of Experimental Agriculture, v.10, n.3, p.1-7, 2016. DOI: http://dx.doi.org/10.9734/ajea/2016/21730

BOHM, G.; SCHWANZ, S.; LANIUS, S.; MORAES, E.; MORSELE, T.. Physical-chemical Characterization and Microbial Activity of Alternative Substrates for Arugula Cultivation (Eruca sativa Mill.). Asian Journal of Soil Science and Plant Nutrition, v.2, n.3, p.1-8, 2018. DOI:

http://www.sciencedomain.org/abstract/22585

BORTOLON, L.; GIANELLO, C.. Disponibilidade de cobre e zinco em solos do sul do Brasil. Revista brasileira de ciencia do solo, v.33, n.3, p.647-658, 2009. DOI: http://dx.doi.org/10.1590/s0100-06832009000300017

CAMARGO, R.; CAMARGO, R.; MALDONADO, A. C. D.; SILVA, P. A.; COSTA, T. R.. Biossólido como substrato na produção de mudas de pinhão-manso. Revista Brasileira de Engenharia Agrícola e Ambiental, v.14, n.12, p.1304-1310, 2010. DOI: http://dx.doi.org/10.1590/s141543662010001200008

CONAMA. N.460/2013: Altera a Resolução CONAMA n. 420, que dispõe sobre critérios e valores orientadores de qualidade do solo quanto à presença de substâncias químicas e dá outras providências. 2009.

DUARTE-DAVIDSON, R.; JONES, K. C.. Screening the environmental fate of organic contaminants in sewage sludge applied to agricultural soils: II. The potential for transfers to plants and grazing animals. The Science of the Total Environment, v.185, n.1-3, p.59-70, 1996. DOI:

\section{http://dx.doi.org/10.1016/0048-9697(96)05042-5}

FERRAZ, A. DE V.; POGGIANI, F. Biomassa, nutrientes e metais pesados em raízes de eucaliptos adubados com diferentes lodos de esgoto. CERNE, v.20, n.2, p.311-320, 2014.

FREITAS, E. V. S.; FREITAS, E. V. S.; NASCIMENTO, C. W. A.; GOULART, D. F.; SILVA, J. P. S.. Disponibilidade de cádmio e chumbo para milho em solo adubado com fertilizantes fosfatados. Revista Brasileira de Ciência do Solo, v.33, n.6, p.1899-1907, 2009. DOI: http://dx.doi.org/10.1590/s0100$\underline{06832009000600039}$

GRANSEE, A.; FÜHRS, H.. Magnesium mobility in soils as a challenge for soil and plant analysis, magnesium fertilization and root uptake under adverse growth conditions. Plant and soil, v.368, n.1-2, p.5-21, 2013. DOI: http://link.springer.com/10.1007/s11104-012-1567-y

HORTELLANI, M. A.; SARKIS, J. E. S.; ABESSA, D. M. S.; SOUSA, E. C. P. M.. Avaliação da contaminação por elementos metálicos dos sedimentos do Estuário Santos - São Vicente. Química Nova, v.31, n.1, p.10-19, 2008.

INGELMO, F.; MOLINA, M. J.; SORIANO, M. D.; GALLARDO, A.; LAPEÑA, L.. Influence of organic matter transformations on the bioavailability of heavy metals in a sludge based compost. Journal of Environmental Management, v.95 Suppl, p.S104-9, 2012. DOI: http://dx.doi.org/10.1016/j.jenvman.2011.04.015

KRAMER, L. F. M.; MÜLLER, M. M. L.; TORMENA, C. A.; GENÚ, A. M.; MICHALOVICZ, L.; VICENSI, M.. Atributos químicos do solo associados à produtividade do trigo em um talhão com diferentes potenciais produtivos. Revista Brasileira de Ciência do Solo, v.38, n.4, p.1190-1199, 2014. DOI: http://dx.doi.org/10.1590/s0100-06832014000400015

LI, J.; LUO, G.; GAO, J.; YUAN, S.; DU, J.; WANG, Z...

Quantitative evaluation of potential ecological risk of heavy metals in sewage sludge from three wastewater treatment 
plants in the main urban area of Wuxi, China. Chemistry and Ecology, v.31, n.3, p.235-251, 2015.

LLORENS, N.; AROLA, L.; BLADÉ, C.; MAS, A.. Effects of copper exposure upon nitrogen metabolism in tissue cultured Vitis vinifera. Plant Science, v.160, n.1, p.159-163, 2000.

MARANGONI, F. F.; TIRITAN, C. S.; DA ROCHA, E. W. L.; COCATO, D. F.; DE MAGALHÃES, P.. Boro e zinco no sulco de plantio na cultura da cana-de-açúcar. Colloquium Agrariae, v.9, p.21-28, 2013. DOI:

http://dx.doi.org/10.5747/ca.2013.v09.nesp.000117

MARCHESAN, E.; SARTORI, G. M. S.; AVILA, L. A.; MACHADO, S. L. O.; ZANELLA, R.; PRIMEL, E. G.; MACEDO, V. R. M.; MARCHEZAN, M. G.. Resíduos de agrotóxicos na água de rios da Depressão Central do Estado do Rio Grande do Sul, Brasil. Ciência Rural, v.40, n.5, p.1053-1059, 2010. DOI: http://dx.doi.org/10.1590/s0103-84782010005000078

MERLINO, L. C. S.; MELO, W. J.; MACEDO, F. G.; GUEDES, A. C. T. P.; RIBEIRO, M. H.; MELO, V. P.; MELO, G. M. P.. Bário, cádmio, cromo e chumbo em plantas de milho e em latossolo após onze aplicações anuais de lodo de esgoto. Revista Brasileira de Ciência do Solo, v.34, n.6, p.2031-2039, 2010. DOI: http://dx.doi.org/10.1590/s010006832010000600027

MOREIRA, A.; MALAVOLTA, E.. Dinâmica da matéria orgânica e da biomassa microbiana em solo submetido a diferentes sistemas de manejo na Amazônia Ocidental. Pesquisa Agropecuária Brasileira, v.39, n.11, p.1103-1110, 2004. DOI: http://dx.doi.org/10.1590/s0100-204x2004001100008

PEARSON, G. S.. International Union of Pure and Applied Chemistry (IUPAC) Working Party on Chemical Weapons Destruction Technologies. Dismantlement and Destruction of Chemical, Nuclear and Conventional Weapons, v.10, p.151-152, 1997. DOI: http://dx.doi.org/10.1007/978-94017-1276-7 33

PINTO, A. M. T.; HIRDES, I. M.; SANCHES-FILHO, P. J.. Determinação de metais pesados nos camarões (Farfantepenaeus paulensis) consumidos na cidade de Pelotas-RS. Journal of the Brazilian Society of Ecotoxicology, v.8, n.1, p.129-134, 2013. DOI: http://dx.doi.org/10.5132/eec.2013.01.019

SCHMITZ, J. A. K.; DE SOUZA, P. V. D.; KÄMPF, A. N.. Propriedades químicas e físicas de substratos de origem mineral e orgânica para o cultivo de mudas em recipientes. Ciência Rural, v.32, n.6, p.937-944, 2002. DOI: http://dx.doi.org/10.1590/s0103-84782002000600005

SILVEIRA, C.; KOGA, D. S.; KURODA, E. K.. Estudo da viabilidade de disposição final dos lodos de ETAS em aterros sanitários. Periódico Eletrônico Fórum Ambiental da Alta Paulista, v.9, n.11, 2013. DOI: http://dx.doi.org/10.17271/198008279112013675

TEDESCO, S. A.. Microbiological Methods. Surface Geochemistry in Petroleum Exploration, p.132-143, 1995. DOI: http://dx.doi.org/10.1007/978-1-4615-2660-5 9

VIEIRA, G. D.; CASTILHOS, D. D.; CASTILHOS, R. M. V.. Atributos microbianos do solo após a adição de lodo anaeróbio da estação de tratamento de efluentes de parboilização do arroz. Revista Brasileira de Ciência do Solo, v.35, n.2, p.543-550, 2011. DOI: http://dx.doi.org/10.1590/s0100-06832011000200023

VILLANUEVA, F. C. A.; BOARETTO, A. E.; FIRME, L. P.; MURAOKA, T.; NASCIMENTO FILHO, V. F.; ABREU JUNIOR, C. $\mathrm{H}$.. Mudanças químicas e fitodisponibilidade de zinco estimada por método isotópico, em solo tratado com lodo de esgoto. Química Nova, v.35, n.7, p.1348-1354, 2012. DOI: http://dx.doi.org/10.1590/s0100-40422012000700012

A CBPC - Companhia Brasileira de Produção Científica (CNPJ: 11.221.422/0001-03) detém os direitos materiais desta publicação. Os direitos referem-se à publicação do trabalho em qualquer parte do mundo, incluindo os direitos às renovações, expansões e disseminações da contribuição, bem como outros direitos subsidiários. Todos os trabalhos publicados eletronicamente poderão posteriormente ser publicados em coletâneas impressas sob coordenação da Sustenere Publishing, da Companhia Brasileira de Produção Científica e seus parceiros autorizados. Os (as) autores (as) preservam os direitos autorais, mas não têm permissão para a publicação da contribuição em outro meio, impresso ou digital, em português ou em tradução. 